\title{
Spatiotemporal Variation in Land Use of Northeast China Tiger and Leopard National Park
}

\author{
Hongqiao Wang ${ }^{1 *}$, Shuang Cheng ${ }^{2}$ \\ ${ }^{1}$ College of Economics and Management, Jilin Agricultural University, Changchun 130118, China \\ ${ }^{2}$ School of Chinese Medicinal Materials, Jilin Agricultural University, Changchun 130118, China
}

Corresponding Author Email: wanghq921@126.com

https://doi.org/10.18280/ijdne.150609

Received: 8 July 2020

Accepted: 5 October 2020

\section{Keywords:}

land use, spatiotemporal variation, ecoenvironment, Northeast China Tiger and Leopard National Park (NCTLNP)

\begin{abstract}
This paper attempts to disclose the law of land use variation in the Northeast China Tiger and Leopard National Park (NCTLNP), and provide theoretical basis for ecoenvironment protection of the national park in future. The data on land use variation in four phases (i.e., 1995, 2005, 2015, and 2018) were selected for analysis based on the geographical information system (GIS). The variation and transfer features of land use were quantified, with the aid of single land use dynamic degree, comprehensive land use dynamic degree, and land use transfer matrix. The results show that: (1) In 1995-2008, the main land types in the NCTLNP were forest, grassland, and cultivated land, which took up more than $90 \%$ of the total area; the grassland area increased, while the areas of cultivated land and forest declined; forest was the land use with the largest transfer-out area $\left(523.59 \mathrm{~km}^{2}\right)$, about $55.29 \%$ of the total transfer-out area in the study area; (2) In the sample period, NCTLNP witnessed significant transfers between land uses; the transfers mostly occurred between forest, grassland, and cultivated land; forest transfers were observed in every county and city; the transfer of forest to grassland mainly concentrated in Dongning City. The research results lay the basis for building up a stereo ecoenvironment monitoring network in the study area, and provide the research direction for eco-environment protection in the NCTLNP.
\end{abstract}

\section{INTRODUCTION}

In recent decades, the research into global environment change has deepened continuously. Land use, as the main content of global environmental studies, becomes the frontier and hotspot of geography and ecology research $[1,2]$. The variation in land use not only causes huge changes in surface structure, but also directly affects the regional atmosphere, soil, and hydrology, as well as the biogeochemical cycle. The variation brings changes to the type, pattern, and process of the ecosystem, and bears on the ecosystem services [3-6].

Over the time, scientific issues like the dynamics, trends, and drivers of land use structure have received extensive attention, and the relevant research has been carried out on different scales [7]. Many studies [8-11] have shown that land use varies significantly between time periods or spatial regions, exerting an impact on the eco-environment. The variation in land use is attributable to various factors. Without considering the lag effect of climate change, human activities are the primary driver of land use variation. To promote regional sustainable development, it is important to gain insights into land use variation, which is a prerequisite for ecosystem management [12].

With the goal of building a national park system, China has rolled out multiple policies on national parks, and accelerated the construction of national parks. In the context of ecological civilization, the growing importance of building a national park system has gained social awareness [13, 14]. As a populous country with limited per-capita land area, China needs to coordinate the relationship between human and land in pursuit the ecological civilization. To disclose the changes in ecosystem, the key is to timely acquire the land use variation in national parks.

Nevertheless, there are relatively few reports on how land use variation affects the ecosystem service value of national parks. Through scenario analysis, some foreign scholars have evaluated the impact of future land use variation on ecosystem services of national parks $[15,16]$. Some domestic scholars have analyzed the land use and eco-environment in different national parks $[17,18]$.

Northeast China Tiger and Leopard National Park (NCTLNP) is a nature reserve that mainly protects rare wild animals. With abundant forest resources, the eco-environment of the NCTLNP has drawn much attention. Many scholars have investigated the eco-environment changes in the NCTLNP. The existing studies mainly focus on the relationship with community residents, the relationship between eco-environment and regional economy [19], as well as the current problems and solutions. There is little research into the influence of land use variation on eco-environment.

Referring to the Master Plan for Northeast China Tiger and Leopard National Park, this paper attempts to disclose the law of land use variation in the NCTLNP, and provide theoretical basis for eco-environment protection of the national park in future. Based on the geographical information system (GIS) software, the land use data of the NCTLNP in four phases of 1995-2018 were collected and interpreted, and the spatiotemporal variation in the structure and distribution of land use were discussed in terms of dynamic degrees and transfer matrix, revealing the trend and phased transfer of land use. 


\section{OVERVIEW OF STUDY AREA}

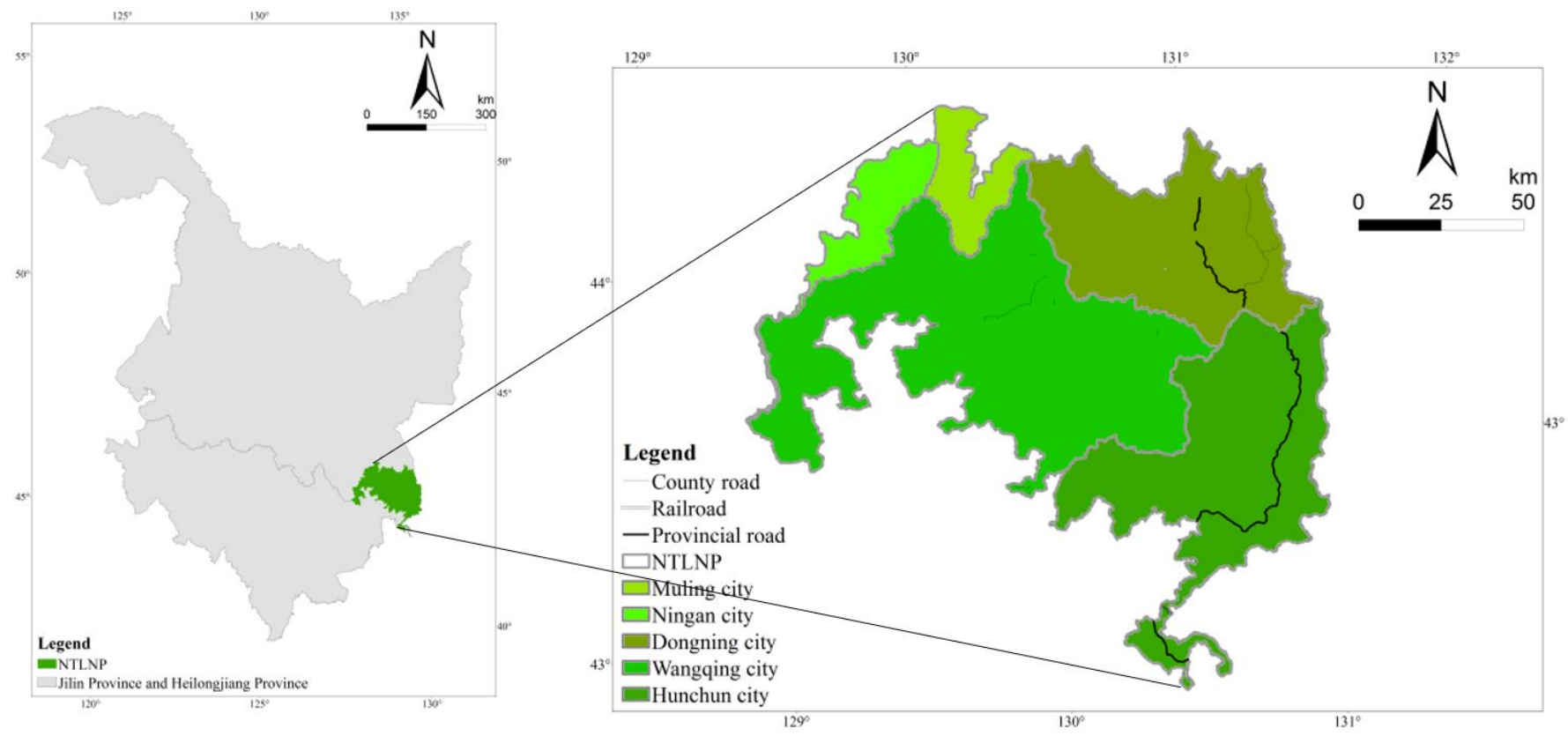

Figure 1. The study area

Adjacent to the Primorsky Krai, Russia, the NCTLNP (N: $42^{\circ} 31^{\prime} 06^{\prime \prime}-44^{\circ} 14^{\prime} 49^{\prime \prime}$; E: $\left.129^{\circ} 5^{\prime} 0^{\prime \prime} \sim 131^{\circ} 18^{\prime} 48^{\prime \prime}\right)$ covers a total area of $14,612 \mathrm{~km}^{2}$ in the south of Laoye Ridge at the junction of Jilin Province and Heilongjiang Province (Figure 1). $10,380 \mathrm{~km}^{2}(71 \%)$ of the national park belongs to Jilin Province, and the remaining $4,232 \mathrm{~km}^{2}$ (29\%) belongs to Heilongjiang Province.

The NCTLNP is bordered by Qinglongtai Forest Farm, Hunchun Forestry Bureau, Jilin Province in the east, Nangou Forestry Farm, Wangqing County Forestry Bureau, Jilin Province in the west, Jingxin Forestry Farm, Hunchun Forestry Bureau, Jilin Province in the south, and Fendou Forest Farm, Dongjingcheng Forestry Bureau, Heilongjiang Province in the north.

Forest ecosystem dominates the study area, sheltering various wild animals and plants. The NCTLNP has complex and diverse landforms, mainly including low and middle mountains, valleys, and hills. The annual mean temperature is $5^{\circ} \mathrm{C}$, and the annual precipitation falls within $450-750 \mathrm{~mm}$. About $80 \%$ of the annual precipitation occurs from May to September. Overall, the study area boasts an excellent ecoenvironment [20].

\section{METHODOLOGY}

\subsection{Data sources and preprocessing}

The land use data of the NCTLNP in 1995, 2005, 2015, and 2018 were collected from the Resource and Environment Science and Data Center, Institute of Geographic Sciences and Natural Resources Research, Chinese Academy of Sciences [21]. The maps were extracted from the Master Plan for Northeast China Tiger and Leopard National Park. The data on social economy, population, environment, and ecology, as well as local land use policies were obtained from the official websites and statistical yearbooks 2018 of the counties and cities in the study area, and the relevant literature.
The land use data were divided into 6 primary land types, namely, forest, grassland, cultivated land, waters, construction land, and unused land. The forest includes arbor forest, shrub forest, sparse forest, and other forests; the grassland includes high-, medium-, and low-coverage grasslands; the cultivated land includes paddy field and dry field; the waters include rivers, cannels, lakes, reservoirs, and ponds; the construction land includes urban land, rural settlements, and other construction lands; the unused land includes marshland and bare stony land. These data were interpreted and analyzed on ArcGIS 10.2. The other data were preprocessed into useful form by relevant formulas.

\subsection{Formulas}

\subsubsection{Single land use dynamic degree}

The single land use dynamic degree $\mathrm{K}$ reflects the annual variation rate of the area of a land type between the initial phase and the final phase. Drawing on the method of Turner et al. [22], the K value can be calculated by:

$$
\mathrm{K}=\frac{U_{b}-U_{a}}{U_{a}} \times \frac{1}{T} \times 100 \%
$$

where, $\mathrm{K}$ is the single land use dynamic degree (if $\mathrm{K}$ is positive, the area of the land type increases; if $\mathrm{K}$ is negative, the area of the land type decreases; the larger the absolute value of $\mathrm{K}$, the more significant the variation); $U_{a}$ and $U_{b}$ are the area of the land type in the initial phase and the final phase, respectively; $\mathrm{T}$ is the length of the sample period (unit: year).

\subsubsection{Comprehensive land use dynamic degree}

The comprehensive land use dynamic degree $L_{C}$ reflects the comprehensive annual variation rate of the area of all land types. The $L_{C}$ value can be calculated by:

$$
L_{C}=\sum_{i=1}^{n}\left|U_{b i}-U_{a i}\right| / 2 \sum_{i=1}^{n} U_{a i} \times \frac{1}{T} \times 100 \%
$$


where, $U_{a i}$ and $U_{b i}$ are the area of a land type in the initial phase and the final phase, respectively; $\mathrm{T}$ is the length of the sample period (unit: year); $n$ is the number of land types in the study area.

\subsubsection{Land use transfer matrix}

The land use transfer matrix intends to represent the structural features of land use/cover, and the variation direction of land use/cover types. Besides the static information of different land types, the matrix embodies the transfer-in and transfer-out areas of different land types, providing an intuitive picture of the variation in land use [23]. The mathematical expression of the transfer matrix can be established as:

$$
S_{i j}=\left[\begin{array}{cccc}
\mathrm{S}_{11} & \mathrm{~S}_{12} & \cdots & \mathrm{S}_{1 n} \\
\mathrm{~S}_{21} & \mathrm{~S}_{22} & \cdots & \mathrm{S}_{2 n} \\
\cdots & \cdots & \cdots & \mathrm{S}_{12} \\
\mathrm{~S}_{n 1} & \mathrm{~S}_{n 2} & \cdots & \mathrm{S}_{n n}
\end{array}\right]
$$

where, $S_{i j}$ is an $n \times n$ matrix; $S$ is area; $i$ and $j$ are the subscripts of the land type in the initial and final phases, respectively; $n$ is the number of land types in the study area.

\section{RESULTS ANALYSIS}

\subsection{Variation in land use}

\subsubsection{Spatiotemporal variation}

The distribution of land types in the study area in 1995-2018 was parsed on ArcGIS 10.2. As shown in Figure 2, forest, grassland, and cultivated land were the dominant land types in the study area, under the natural constraints of geographic location and topography. Forest covered more than $90 \%$ of the study area. The wide distribution of forest makes it meaningful to explore the ecosystem service value in the study area. By contrast, cultivated land was clustered in several places, namely, Wangqing County, Dongning City, and Hunchun City. The grassland was distributed in patches, scattering across various counties and cities. From 1995 to 2018, the land types in the study area can be ranked in descending order of area as forest $>$ cultivated land $>$ grassland $>$ construction land $>$ unused land $>$ waters.
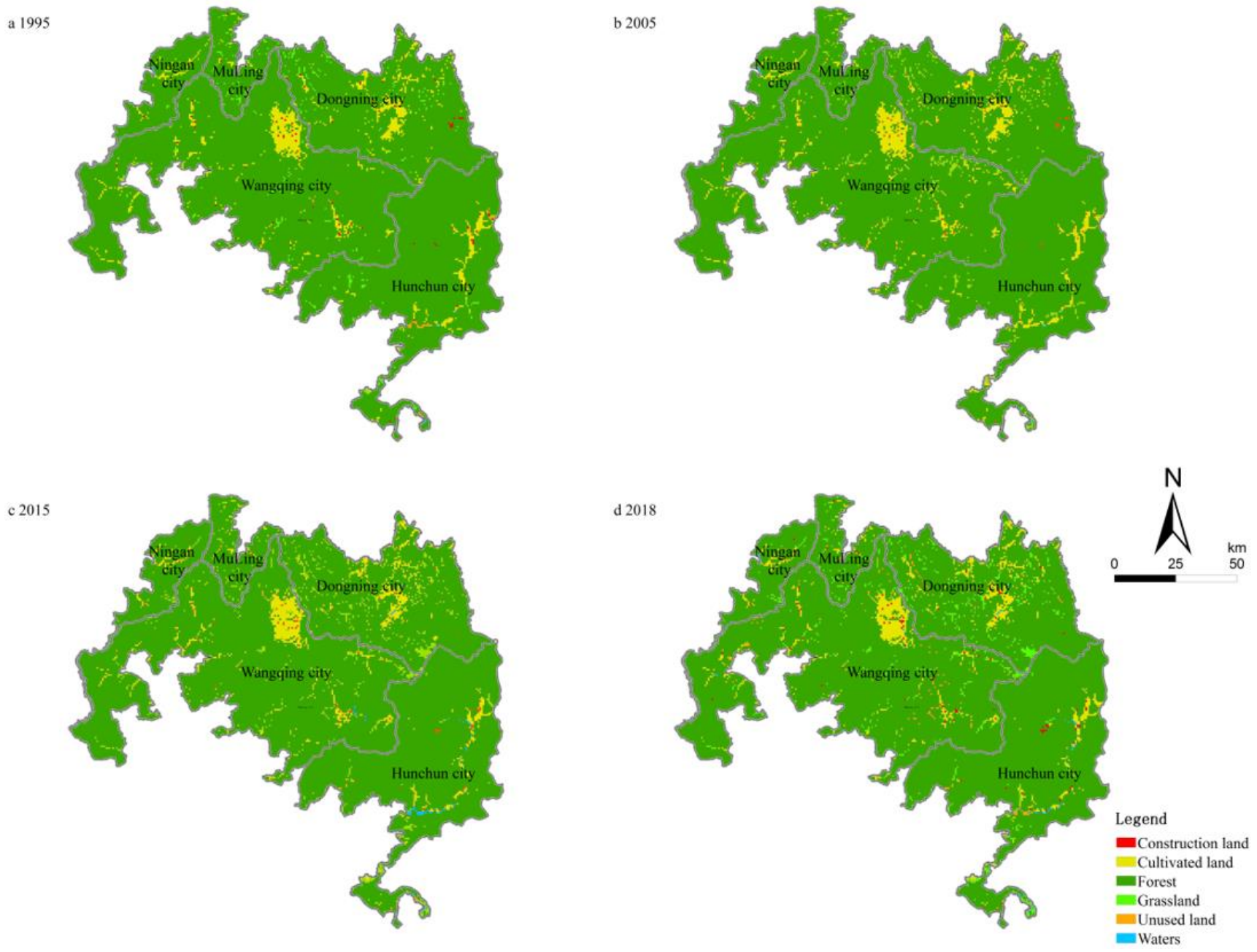

Figure 2. The distribution of land types in the NCTLNP

Based on the distribution of land types, the areas of different land types of the NCTLNP in 1995-2018 were counted, and the structure and dynamic degrees of land use were calculated by the previous formulas (Tables 1-3). The following phenomena can be observed from the results:

During 1955-2018, different land types varied by different degrees. Specifically, the forest area continued to shrink slowly from $13,562.31 \mathrm{~km}^{2}$ in 1955 to $13,303.27 \mathrm{~km}^{2}$ in 2018 , falling by a total of $259.04 \mathrm{~km}^{2}$. However, the area of the primary type of forest, the arbor forest, started to increase since 2015.

The area of cultivated land first decreased and then 
increased. From 1995 to 2018, the area of cultivated land dropped from $792.65 \mathrm{~km}^{2}$ to $747.56 \mathrm{~km}^{2}$.

The dynamic degrees of grassland and waters exhibited an inverted U-shaped curve. From 1995 to 2018, the grassland area increased from $178.87 \mathrm{~km}^{2}$ to $407.35 \mathrm{~km}^{2}$; the area of waters surged up from $11.02 \mathrm{~km}^{2}$ to $32.07 \mathrm{~km}^{2}$.

The area of construction land first decreased and then increased. From 1995 to 2018 , this area expanded from 40.08 $\mathrm{km}^{2}$ to $47.10 \mathrm{~km}^{2}$. Specifically, the area of rural settlements, the dominant type of construction land, reduced from 38.02 $\mathrm{km}^{2}$ in 1995 to $36.54 \mathrm{~km}^{2}$ in 2018 . The slight decline in the area of rural settlements is the result of the pilot of the NCTLNP during the sample period.

The area of unused land increased from $27.06 \mathrm{~km}^{2}$ in 1995 to $74.66 \mathrm{~km}^{2}$ in 2018 . As the main type of unused land, the marshland area jumped from $27.08 \mathrm{~km}^{2}$ in 1995 to $74.63 \mathrm{~km}^{2}$ in 2018, which benefits the inhabitation and reproduction of rare animals like the red-crowned cranes in the study area.

Table 1. The variation in land use structure of the NCTLNP in 1995-2018 $\left(\mathrm{km}^{2}\right)$

\begin{tabular}{ccccccc}
\hline Study phase & Grassland & Cultivated land & Forest & Waters & Construction land & Unused land \\
\hline $\mathbf{1 9 9 5}$ & 178.87 & 792.65 & 13562.31 & 11.02 & 40.08 & 27.06 \\
$\mathbf{2 0 0 5}$ & 264.53 & 818.65 & 13453.66 & 13.03 & 37.07 & 25.05 \\
$\mathbf{2 0 1 5}$ & 505.54 & 695.43 & 13316.84 & 39.58 & 41.59 & 13.03 \\
$\mathbf{2 0 1 8}$ & 407.35 & 747.56 & 13303.27 & 32.07 & 47.10 & 74.66 \\
\hline
\end{tabular}

Table 2. The secondary classes of land use of the NCTLNP in 1995-2018 $\left(\mathrm{km}^{2}\right)$

\begin{tabular}{|c|c|c|c|c|c|}
\hline & & 1995 & 2005 & 2015 & 2018 \\
\hline \multirow{3}{*}{ Cultivated land } & paddy field & 88.34 & 82.34 & 92.30 & 21.36 \\
\hline & dry farmland & 689.17 & 729.63 & 598.52 & 719.78 \\
\hline & forest land & 13158.56 & 13056.14 & 13216.74 & 13231.56 \\
\hline \multirow{3}{*}{ Forest } & shrubs & 158.36 & 162.58 & 87.74 & 83.39 \\
\hline & open forest land & 130.33 & 120.90 & 1.68 & 0.83 \\
\hline & Other Forest & 119.74 & 115.82 & 12.86 & 7.31 \\
\hline \multirow{3}{*}{ Grassland } & High coverage grassland & 178.64 & 193.34 & 476.73 & 374.65 \\
\hline & Medium coverage of grassland & 4.29 & 74.49 & 31.39 & 23.84 \\
\hline & canal & 0.21 & 0.21 & 6.43 & 8.53 \\
\hline \multirow{4}{*}{ Waters } & lake & 4.86 & 4.60 & 5.84 & 5.86 \\
\hline & reservoir & 3.90 & 4.68 & 3.24 & 6.96 \\
\hline & shoaly land & 2.23 & 2.23 & 22.93 & 7.82 \\
\hline & urban land & 0.13 & 0.14 & 0.13 & 1.25 \\
\hline \multirow[t]{2}{*}{ Construction land } & rural settlement & 38.02 & 33.85 & 37.84 & 36.54 \\
\hline & Other Construction land & 6.48 & 6.48 & 5.50 & 7.69 \\
\hline \multirow{2}{*}{ Unused land } & wetlands & 27.80 & 24.07 & 11.76 & 74.63 \\
\hline & Bare rock stony ground & 0.94 & 0.49 & 0.37 & 0.00 \\
\hline
\end{tabular}

Table 3. The distribution of land use dynamic degrees of the NCTLNP in 1995-2018 (\%)

\begin{tabular}{cccccccc}
\hline \multirow{2}{*}{$\begin{array}{c}\text { Study } \\
\text { phase }\end{array}$} & \multicolumn{9}{c}{ Single land use type dynamic index K } & Comprehensive land use type dynamic \\
index $L_{C}$ & $\begin{array}{c}\text { Unused } \\
\text { land }\end{array}$ & Construction \\
$\mathbf{1 9 9 5 - 2 0 0 5}$ & 4.79 & 0.33 & -0.08 & 1.82 & -0.75 & -0.74 & 0.08 \\
$\mathbf{2 0 0 5 - 2 0 1 5}$ & 9.11 & -1.51 & -0.10 & 20.39 & 1.22 & -4.80 & 0.19 \\
$\mathbf{2 0 1 5 - 2 0 1 8}$ & -6.47 & 2.50 & -0.03 & -6.33 & 4.42 & 157.70 & 0.27 \\
$\mathbf{1 9 9 5 - 2 0 1 8}$ & 5.55 & -0.25 & -0.08 & 8.30 & 0.76 & 7.65 & 0.09 \\
\hline
\end{tabular}

From 1995 to 2005, the comprehensive land use dynamic degree was $0.08 \%$. By single land use dynamic degree, the different land uses can be ranked in descending order as grassland $>$ waters $>$ construction land $>$ unused land $>$ cultivated land $>$ forest. The corresponding single land use dynamic degrees were $4.79 \%, 1.82 \%,-0.75 \%,-0.74 \%, 0.33 \%$, and $0.08 \%$ in turn.

From 2005 to 2015 , the comprehensive land use dynamic degree was $0.19 \%$. By single land use dynamic degree, the different land uses can be ranked in descending order as waters $>$ grassland $>$ unused land $>$ cultivated land $>$ construction land $>$ forest. The corresponding single land use dynamic degrees were $20.39 \%, 9.11 \%,-4.80 \%,-1.51 \%, 1.22 \%$, and $0.10 \%$ in turn.

From 2015 to 2018, the comprehensive land use dynamic degree was $0.27 \%$. By single land use dynamic degree, the different land uses can be ranked in descending order as unused land $>$ grassland $>$ waters $>$ construction land $>$ cultivated land $>$ forest. The corresponding single land use dynamic degrees were $157.70 \%,-6.47 \%,-6.33 \%, 4.42 \%, 2.50 \%$, and $0.03 \%$ in turn.

From 1995 to 2018 , the comprehensive land use dynamic degree was $0.09 \%$. By single land use dynamic degree, the different land uses can be ranked in descending order as waters $>$ unused land $>$ grassland $>$ construction land $>$ cultivated land $>$ forest. The corresponding single land use dynamic degrees were $8.30 \%, 7.56 \%, 5.55 \%, 0.76 \%,-0.25 \%$, and $0.08 \%$ in turn. Overall, forest had the smallest dynamic degree, a sign of slow variation; unused land had the largest dynamic degree, an evidence to its extreme instability.

\subsubsection{Transfer of land types}

The previous analysis shows signifciant variation in the land uses of the NCTLNP in 1995-2018. To intuitively reflect the 
transfer of land types in the sample period, the land use data of every two adjacent phases were spatially superimposed on ArcGIS 10.2 to obtain the land use transfer matrices of 19952005, 2005-2015, 2015-2018, and 1995-2018 (Tables 4-7).

As shown in Table 4, the different land uses in 1995-2005 can be ranked in descending order of transfer-out area as forest $>$ cultivated land $>$ grassland $>$ unused land $>$ construction land $>$ waters. The corresponding transfer-out areas were
$181.87 \mathrm{~km}^{2}, 73.15 \mathrm{~km}^{2}, 30.06 \mathrm{~km}^{2}, 5.51 \mathrm{~km}^{2}, 3.51 \mathrm{~km}^{2}$, and 0 $\mathrm{km}^{2}$ in turn; the different land uses in the same period can be ranked in descending order of transfer-in area as grassland $>$ cultivated land $>$ forest $>$ unused land $>$ waters $>$ construction land. The corresponding transfer-in areas were $115.73 \mathrm{~km}^{2}, 99.20 \mathrm{~km}^{2}, 73.15 \mathrm{~km}^{2}, 3.51 \mathrm{~km}^{2}$, and $2.00 \mathrm{~km}^{2}$ in turn.

Table 4. The land use transfer matrix of the NCTLNP in 1995-2005 $\left(\mathrm{km}^{2}\right)$

\begin{tabular}{ccccccc}
\hline \multirow{2}{2005}{} & \multicolumn{5}{c}{$\mathbf{1 9 9 5}$} \\
\cline { 2 - 6 } Grassland & Grassland & Cultivated land & Construction land & Forest & Waters & Unused land \\
Cultivated land & 148.80 & 19.54 & & 96.19 & & \\
Construction land & 10.52 & 719.45 & 2.51 & 83.17 & & 3.01 \\
Forest & 19.54 & 50.10 & 36.57 & & & 2.51 \\
Waters & & 1.50 & 1.00 & 13380.51 & & \\
Unused land & & 1.50 & & 2.50 & 11.02 & 21.54 \\
\hline
\end{tabular}

Table 5. The land use transfer matrix of the NCTLNP in $2005-2015\left(\mathrm{~km}^{2}\right)$

\begin{tabular}{ccccccc}
\hline \multirow{2}{*}{$\mathbf{2 0 1 5}$} & \multicolumn{7}{c}{$\mathbf{2 0 0 5}$} \\
\cline { 2 - 7 } Grassland & Grassland & Cultivated land & Construction land & Forest & Waters & Unused land \\
Cultivated land & 118.74 & 112.72 & 4.01 & 265.53 & 1.00 & 3.51 \\
Construction land & 7.01 & 535.56 & 10.02 & 136.27 & 3.01 & 3.51 \\
Forest & 0.50 & 16.53 & 16.03 & 7.51 & & 1.00 \\
Waters & 137.27 & 138.78 & 6.51 & 13028.86 & & 5.51 \\
Unused land & 1.00 & 9.52 & 0.50 & 9.52 & 8.52 & 10.52 \\
\hline
\end{tabular}

Table 6. The land use transfer matrix of the NCTLNP in $2015-2018\left(\mathrm{~km}^{2}\right)$

\begin{tabular}{ccccccc}
\hline \multirow{2}{2}{2018} & \multicolumn{7}{c}{$\mathbf{2 0 1 5}$} \\
\cline { 2 - 7 } Grassland & Grassland & Cultivated land & Construction land & Forest & Waters & Unused land \\
Cultivated land & 385.29 & 2.51 & 0.50 & 16.03 & 0.00 & 3.01 \\
Construction land & 53.61 & 639.81 & 3.01 & 47.10 & 3.01 & 1.50 \\
Forest & 0.00 & 4.01 & 37.58 & 5.51 & 0.00 & 0.00 \\
Waters & 37.08 & 42.59 & 0.50 & 13220.64 & 1.00 & 1.00 \\
Unused land & 0.50 & 5.01 & 0.00 & 1.50 & 25.05 & 0.00 \\
\hline
\end{tabular}

Table 7. The land use transfer matrix of the NCTLNP in $1995-2018\left(\mathrm{~km}^{2}\right)$

\begin{tabular}{|c|c|c|c|c|c|c|}
\hline \multirow{2}{*}{2018} & \multicolumn{6}{|c|}{1995} \\
\hline & Grassland & Cultivated land & Construction land & Forest & Waters & Unused land \\
\hline Grassland & 75.16 & 65.14 & 3.01 & 261.04 & 1.00 & 2.00 \\
\hline Cultivated land & 13.53 & 515.08 & 11.52 & 199.42 & 0.50 & 7.52 \\
\hline Construction land & 0.50 & 17.04 & 16.53 & 13.03 & 0.00 & 0.00 \\
\hline Forest & 78.16 & 172.86 & 7.52 & 13038.72 & 0.00 & 6.01 \\
\hline Waters & 1.00 & 14.53 & 0.50 & 5.01 & 9.52 & 1.50 \\
\hline Unused land & 10.52 & 8.02 & 1.00 & 45.09 & 0.00 & 10.02 \\
\hline
\end{tabular}

As shown in Table 5, the different land uses in 2005-2015 can be ranked in the same descending order of transfer-out area as those in the previous period. The corresponding transfer-out areas were $424.84 \mathrm{~km}^{2}, 283.06 \mathrm{~km}^{2}, 145.79 \mathrm{~km}^{2}$, $24.05 \mathrm{~km}^{2}, 21.04 \mathrm{~km}^{2}$, and $4.51 \mathrm{~km}^{2}$ in turn; the different land uses in the same period can be ranked in descending order of transfer-in area as grassland $>$ forest $>$ cultivated land $>$ waters $>$ construction land $>$ unused land. The corresponding transfer-in areas were $386.77 \mathrm{~km}^{2}, 288.07 \mathrm{~km}^{2}$, $159.82 \mathrm{~km}^{2}, 31.06 \mathrm{~km}^{2}, 25.55 \mathrm{~km}^{2}$, and $12.02 \mathrm{~km}^{2}$ in turn.

As shown in Table 6, the different land uses in 2015-2018 can be ranked in descending order of transfer-out area as grassland $>$ forest $>$ cultivated

land $>$ waters $>$ unused land $>$ construction land. The corresponding transfer-out areas were $120.25 \mathrm{~km}^{2}, 96.20 \mathrm{~km}^{2}, 55.61 \mathrm{~km}^{2}, 14.53 \mathrm{~km}^{2}, 5.51 \mathrm{~km}^{2}$, and $4.01 \mathrm{~km}^{2}$ in turn; the different land uses in the same period can be ranked in descending order of transfer-in area as cultivated land $>$ forest $>$ unused land $>$ grassland $>$ construction land $>$ waters. The corresponding transfer-in areas were 108.22 $\mathrm{km}^{2}, 82.17 \mathrm{~km}^{2}, 67.14 \mathrm{~km}^{2}, 22.05 \mathrm{~km}^{2}, 9.52 \mathrm{~km}^{2}$, and $7.01 \mathrm{~km}^{2}$ in turn.

As shown in Table 7, the transfer of different land uses in 1995-2018 carry two prominent features. On the transfer-out area, forest had the greatest transfer-out area $\left(523.59 \mathrm{~km}^{2}\right)$, taking up more than half $(55.29 \%)$ of the total transfer-out area. Cultivated land had the second largest transfer-out area 
$\left(277.58 \mathrm{~km}^{2}\right)$, taking up $29.31 \%$ of the total. The transfer-out area of grassland stood at $103.72 \mathrm{~km}^{2}, 10.95 \%$ of the total. The transfer-out areas of construction land, unused land, and waters were relatively small: $23.55 \mathrm{~km}^{2}(2.49 \%), 17.04 \mathrm{~km}^{2}$ $(1.80 \%)$, and $1.50 \mathrm{~km}^{2}(0.16 \%)$.

On the transfer-in area, grassland had the greatest transferin area $\left(332.19 \mathrm{~km}^{2}\right)$, taking up more than $1 / 3$ of the total transfer-in area. Forest had the second largest transfer-in area $\left(264.55 \mathrm{~km}^{2}\right)$, followed by cultivated land $\left(232.49 \mathrm{~km}^{2}\right)$. The transfer-in areas of construction land, unused land, and waters were relatively small: $30.56 \mathrm{~km}^{2}, 64.63 \mathrm{~km}^{2}$, and $22.55 \mathrm{~km}^{2}$.

To sum up, some forest areas were transferred out into land types with small unit value of ecosystem services, namely, grassland and cultivated land. The ensuing reduction in forest area is not conducive to the maintenance and protection of ecoenvironment in the NCTLNP.
From the land use transfer map of the NCTLNP in the sample period (Figure 3), it is learned that land use transfers occurred in all four phases. The most significant transfers appeared in 2005-2015. The main land use types involved in transfer-in and transfer-out were forest, cultivated land, and grassland. Specifically, forest was mainly transferred out to cultivated land and grassland. The transfer of forest to grassland concentrated in the northeast of Wangqing County and the southeast of Dongning City; the transfer of forest to cultivated land was scattered in patches in various counties and cities. The transfer of grassland to cultivated land concentrated in Hunchun City. The transfer of cultivated land to grassland took place in a scattered manner. Throughout the sample period, the land type variation was rather complex, and the largest transfer-out occurred to forest.

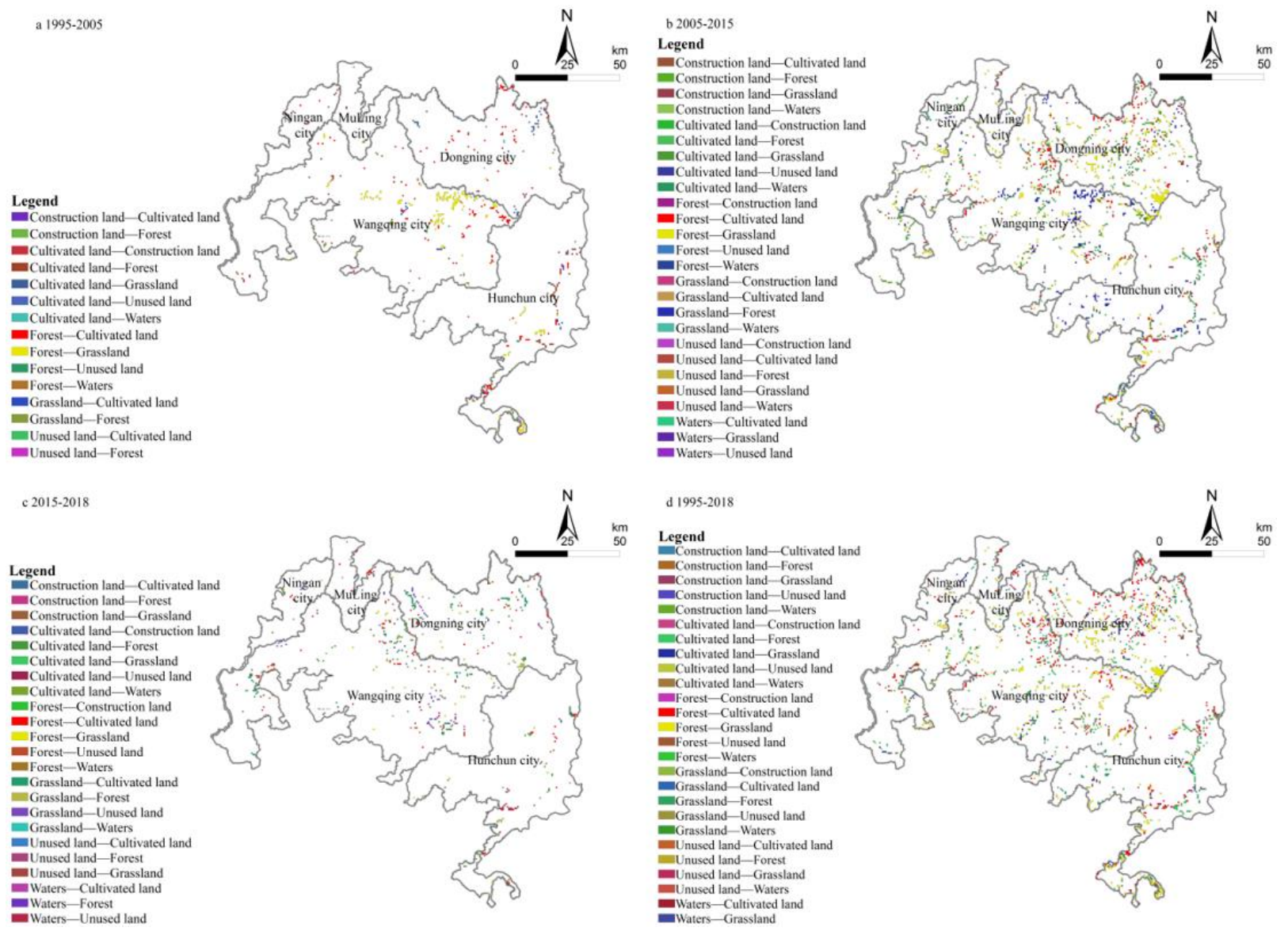

Figure 3. The geographical distribution of land use transfers in the NCTLNP

\section{CONCLUSIONS}

This paper analyzes the distribution of land use in 1995, 2005, 2015, and 2018 of the NCTLNP, and reveals the spatiotemporal laws of land use variation, using single land use dynamic degrees, comprehensive land use dynamic degree, and land use transfer matrices. The main conclusions are as follows:

\subsection{The study area underwent significant variation in land use structure}

From 1995 to 2018, the forest remained as the dominant type of land use in the NCTLNP, taking up more than $90 \%$ of the total area; waters had a smaller area than any other land use, accounting for about $0.15 \%$ of the total area. By mean area, the land types can be ranked in descending order as forest $>$ cultivated land $>$ grassland $>$ construction land $>$ unused land $>$ waters.

Specifically, the forest area exhibited a decreasing trend, but the area of arbor forest increased since 2015. The area of cultivated land first decreased and then increased. The grassland area continued to decline. The water area kept expanding, but shrunk in recent years. The area of construction land was on the rise, but the dominant type of construction land, rural settlements, saw a decrease in area, which is in line of the policy of reducing human activities in the study area. The area of unused land expanded in recent years. Marshland, 
as the dominant type of unused land surged up, mainly in Wangqing County, with a change rate of $157.70 \%$. This benefits the inhabitation and reproduction of rare animals like the red-crowned cranes, and promotes the eco-environment.

\subsection{The transfers between land types were very active}

(1) From 1995 to 2005 , the local demand for land in the region remained stable. About $0.5 \mathrm{~km}^{2}$ of cultivated land was transferred into construction land. Forest, cultivated land, and grassland were the main land types involved in land transfers.

Forest was mainly transferred out into grassland and cultivated land. The transfer of forest to grassland mostly occurred in Wangqing County; the transfer of forest to cultivated land mostly occurred in Wangqing County, Dongning City, and Hunchun City; only a few amounts of forest was transferred out as waters, and unused land.

Cultivated land was mainly transferred out as grassland and forest. The transfer of cultivated land to forest mostly occurred in Hunchun City, indicating that the city implemented the Grain for Green project in this period. Besides, a few amounts of cultivated land were transferred out into waters and unused land.

Grassland was mainly transferred out cultivated land and forest. The transfer of grassland to forest mainly occurred in Hunchun City, and Wangqing County; the transfer of grassland to cultivated land mainly occurred in Dongning City.

Unused land was mainly transferred out to cultivated land and forest, mainly in Hunchun City and Wangqing County.

Construction land wass mainly transferred out to cultivated land and forest, mainly in Wangqing County, Hunchun City, and Muling City.

(2) 2005-2015 was the most active phase of land transfers. With the development of the economy, the local demand for land resources increased in this period. A total of $25.55 \mathrm{~km}^{2}$ of construction land was transferred in. The sources were mainly cultivated land and forest in various counties and cities. The amount of transfer was rather small. In addition, a few amounts of construction land were transferred in from grassland and unused land.

The transfer-in area of waters was $31.06 \mathrm{~km}^{2}$, mainly from forest, cultivated land, and unused land. The transfer in mostly occurred in Hunchun City.

The transfer-in area of unused land was $12.02 \mathrm{~km}^{2}$, mainly from forest and cultivated land, and a few from waters.

Forest was mainly transferred out as grassland and cultivated land. The transfer of forest to grassland concentrated in Dongning City, while that of forest to cultivated land was distributed in patches across the various counties and cities.

Cultivated land was mainly transferred out as forest and grassland. The transfer to forest mainly occurred in Hunchun City, Dongning City, and Wangqing County, while that to grassland concentrated in Dongning City.

Grassland was mainly transferred out to forest, and cultivated land. The transfer mostly took place in Hunchun City, Dongning City, and Wangqing County.

(3) The land transfers were relatively stable in 2015-2018. The transfer-in area $\left(9.52 \mathrm{~km}^{2}\right)$ and transfer-out area $\left(4.01 \mathrm{~km}^{2}\right)$ of construction land were relatively small. The main sources of transfer-in were forest and cultivated land.

Unused land had a large transfer-in area, mainly from grassland, forest, and waters. The transfers mostly took place in Hunchun City, and Wangqing County.
The transfer-in area of waters was $7.01 \mathrm{~km}^{2}$, mainly from cultivated land. The transfers mostly occurred in Wangqing County.

Forest was mainly transferred out to grassland, cultivated land, and unused land. The transfers were distributed in various counties and cities.

Cultivated land was mainly transferred out to forest. The transfers occurred in Wangqing County, Hunchun City, and Dongning City.

Grassland was mainly transferred out to cultivated land, forest, and unused land. The transfers are mostly clustered in Dongning City.

The NCTLNP is a nature reserve mainly for the protection of Siberian tigers and leopards. The growth of arbor forest since 2015 benefits the habitation and reproduction of rare animals like Siberian tigers, leopards, sika deer, and sables. The expansion of marshland favors the habitation and reproduction of rare animals that mainly inhabit the marsh, namely, red-crowned cranes.

According to the Master Plan for Northeast China Tiger and Leopard National Park, the core protection area is mainly distributed in Hunchun City, Wangqing County, and Dongning City; in the northeast of the study area, there are scattered urban security protection zones between the core protection area and the recovery diffusion area. Through ArcGIS analysis on land use and roads in the study area, it can be seen that the provincial roads and county roads in the core protection area have become obstacles between the core protection area and the recovery diffusion area.

Our research results show that construction land is mainly distributed in Hunchun City, Wangqing County, and Dongning City, and less distributed in the other two county/city. Compared with 1995, the area of construction land in Dongning City shrunk, while that in Hunchun City and Wangqing County slightly increased. Therefore, Hunchun City and Wangqing County should pay more attention to the management and control of construction land, and actively implement the policy of reducing human activities in the study area

The pilot program of the NCTLNP was launched in 2017. The relevant data have not been compiled and published. Therefore, it is difficult for us to acquire the complete data after the launch. The variation trend of forest might not fit with reality. However, the growth of arbor forest area, which is the main type of forest, is in line with the actual trend.

In the future research, the authors will collect more complete data, and further analyze the change law of land uses in the study area. For example, the future research could analyze the root causes of the variation in land uses that benefit the eco-environment, e.g., forest and waters, maintain the area of these land types at the source, and actively expand the area of such lands. In addition, the change law of ecosystem could be discussed based on the variation in land uses, and the land use pattern could be rationalized through planning, such that the study area could realize sustainable development of ecosystem, and achieve the harmonious development of animals, eco-environment, and humans.

\section{ACKNOWLEDGEMENTS}

The project was founded by Jilin Institute of Higher Education: Practice and Exploration of Training Compound Tourism Talents for Rural Revitalization Strategy (Grant No.: JGJX2019B12) 


\section{REFERENCES}

[1] Li, Y.C., Li, J.S. (2017). A Spatio-Temporal process expression model for land cover based on process object. Journal of Jilin University (Earth Science Edition), 3: 25.

[2] Foley, J.A., DeFries, R., Asner, G.P., Barford, C., Bonan, G., Carpenter, S.R., Helkowski, J.H. (2005). Global consequences of land use. Science, 309(5734): 570-574. https://doi.org/10.1126/science. 1111772

[3] Swetnam, R.D., Fisher, B., Mbilinyi, B.P., Munishi, P. K., Willcock, S., Ricketts, T., Lewis, S.L. (2011). Mapping socio-economic scenarios of land cover change: A GIS method to enable ecosystem service modelling. Journal of Environmental Management, 92(3): 563-574. https://doi.org/10.1016/j.jenvman.2010.09.007

[4] McCune, S. (1937). Land Utilization and Rural Economy in Korea. Economic Geography, 13(2): 212-213. https://doi.org/10.2307/140338

[5] Kusi, K.K., Khattabi, A., Mhammdi, N., Lahssini, S. (2020). Prospective evaluation of the impact of land use change on ecosystem services in the Ourika watershed, Morocco. Land Use Policy, 97: 104796. https://doi.org/10.1016/j.landusepol.2020.104796

[6] Delphin, S., Escobedo, F.J., Abd-Elrahman, A., Cropper, W.P. (2016). Urbanization as a land use change driver of forest ecosystem services. Land Use Policy, 54: 188-199. https://doi.org/10.1016/j.landusepol.2016.02.006

[7] Wang, Z., Cao, J., Zhu, C., Yang, H. (2020). The impact of land use change on ecosystem service value in the upstream of Xiong'an New Area. Sustainability, 12(14): 5707. https://doi.org/10.3390/su12145707

[8] Sleeter, B.M., Liu, J., Daniel, C., Rayfield, B., Sherba, J., Hawbaker, T.J., Loveland, T.R. (2018). Effects of contemporary land-use and land-cover change on the carbon balance of terrestrial ecosystems in the United States. Environmental Research Letters, 13(4): 045006. https://doi.org/10.1088/1748-9326/aab540

[9] Rahaman, S., Kumar, P., Chen, R., Meadows, M.E., Singh, R.B. (2020). Remote sensing assessment of the impact of land use and land cover change on the environment of Barddhaman district, West Bengal, India. Frontiers in Environmental Science, 8.

[10] Kim, M., You, S., Chon, J., Lee, J. (2017). Sustainable land-use planning to improve the coastal resilience of the social-ecological landscape. Sustainability, 9(7): 1086. https://doi.org/10.3390/su9071086

[11] Synes, N.W., Brown, C., Palmer, S.C., Bocedi, G., Osborne, P.E., Watts, K., Travis, J.M. (2019). Coupled land use and ecological models reveal emergence and feedbacks in socio-ecological systems. Ecography, 42(4): 814-825. https://doi.org/10.1111/ecog.04039

[12] Abiodun, O.E., Akinola, D.J. (2019). Mapping the impact of land use and land cover change on urban land and vegetation in Osun State, Nigeria. Nigerian Journal of Environmental Sciences and Technology (NIJEST), 3(2): 317-330. https://doi.org/10.36263/nijest.2019.02.0146

[13] Kun, S., Linsheng, Z., Xiangyuan, M.A. (2017). Increasing the scale and efficiency of finance in constructing and running the Qianjiangyuan National Park System Pilot Area. Resources Science.

[14] He, S., Su, Y., Wang, L., Gallagher, L., Cheng, H. (2018). Taking an ecosystem services approach for a new national park system in China. Resources, Conservation and $\quad$ Recycling, 137: 136-144. https://doi.org/10.1016/j.resconrec.2018.04.030

[15] Mukul, S.A., Sohel, M.S.I., Herbohn, J., Inostroza, L., König, H. (2017). Integrating ecosystem services supply potential from future land-use scenarios in protected area management: A Bangladesh case study. Ecosystem Services, 26: 355-364. https://doi.org/10.1016/j.ecoser.2017.04.001

[16] Eldridge, D.J., Bowker, M.A., Maestre, F.T., Roger, E., Reynolds, J.F., Whitford, W.G. (2011). Impacts of shrub encroachment on ecosystem structure and functioning: towards a global synthesis. Ecology Letters, 14(7): 709722. https://doi.org/10.1111/j.1461-0248.2011.01630.x

[17] Cao, W., Li, R., Chi, X., Chen, N., Chen, J., Zhang, H., Zhang, F. (2017). Island urbanization and its ecological consequences: A case study in the Zhoushan Island, East China. Ecological Indicators, 76: 1-14. https://doi.org/10.1016/j.ecolind.2017.01.001

[18] Sun, X., Li, S., Yu, J., Fang, Y., Zhang, Y., Cao, M. (2019). Evaluation of ecosystem service value based on land use scenarios: A case study of Qianjiangyuan National Park pilot. Biodiversity Science, 27(1): 51. https://doi.org/10.17520/biods.2018182

[19] Liu, Y. (2020). Coupling and cooperative evaluation of ecological environment and regional economic development-a case study of northeast tiger and leopard national park in Hunchun. Journal of Northeast Forestry University, 48(4): 76-80.

[20] Wei, W. (2019). Habitat suitability study of wild Siberian tigers and leopards based on remote sensing and GIS. Jilin University.

[21] Resource environment Science and Data Center [EB/OL]. http://www.resdc.cn/.

[22] Turner, B., Skole, D., Sanderson, S., Fischer, G., Fresco, L., Leemans, R. (1995). Land-use and land-cover change: science/research plan. Global Change Report (Sweden), 43(1995): 669-679.

[23] Zhou, R., Lin, M., Gong, J., Wu, Z. (2019). Spatiotemporal heterogeneity and influencing mechanism of ecosystem services in the Pearl River Delta from the perspective of LUCC. Journal of Geographical Sciences, 29(5): 831-845. https://doi.org/10.1007/s11442-019-1631-0 